Article

\title{
Antiproliferation and Induction of Apoptosis in Ca9-22 Oral Cancer Cells by Ethanolic Extract of Gracilaria tenuistipitata
}

\author{
Chi-Chen Yeh ${ }^{1}$, Chao-Neng Tseng ${ }^{1,2}$, Jing-Iong Yang ${ }^{3}$, Hurng-Wern Huang ${ }^{4}$, Yi Fang ${ }^{2}$, \\ Jen-Yang Tang ${ }^{5,6}$, Fang-Rong Chang ${ }^{1, *}$ and Hsueh-Wei Chang ${ }^{1,2,7, *}$
}

1 Graduate Institute of Natural Products, Kaohsiung Medical University, Kaohsiung 807, Taiwan

2 Department of Biomedical Science and Environmental Biology, Kaohsiung Medical University, Kaohsiung 807, Taiwan

3 Department of Seafood Science, National Kaohsiung Marine University, Kaohsiung 811, Taiwan

4 Institute of Biomedical Science, National Sun Yat-Sen University, Kaohsiung 804, Taiwan

5 Department of Radiation Oncology, Faculty of Medicine, College of Medicine, Kaohsiung Medical University, Kaohsiung 807, Taiwan

6 Department of Radiation Oncology, Kaohsiung Medical University Hospital, Kaohsiung 807, Taiwan

7 Cancer Center, Kaohsiung Medical University Hospital, Kaohsiung Medical University, Kaohsiung 807, Taiwan

* Authors to whom correspondence should be addressed; E-Mails: aaronfrc@kmu.edu.tw (F.-R.C.); changhw@kmu.edu.tw (H.-W.C.); Tel.: +886-7-312-1101 (ext. 2691) (H.-W.C.);

Fax: +886-7-312-5339 (H.-W.C.).

Received: 20 August 2012; in revised form: 6 September 2012 / Accepted: 7 September 2012 / Published: 11 September 2012

\begin{abstract}
The water extract of Gracilaria tenuistipitata have been found to be protective against oxidative stress-induced cellular DNA damage, but the biological function of the ethanolic extracts of G. tenuistipitata (EEGT) is still unknown. In this study, the effect of EEGT on oral squamous cell cancer (OSCC) Ca9-22 cell line was examined in terms of the cell proliferation and oxidative stress responses. The cell viability of EEGT-treated OSCC cells was significantly reduced in a dose-response manner $(p<0.0001)$. The annexin $\mathrm{V}$ intensity and pan-caspase activity of EEGT-treated OSCC cells were significantly increased in a dose-response manner ( $p<0.05$ to 0.0001$)$. EEGT significantly increased the reactive oxygen species (ROS) level $(p<0.0001)$ and decreased the glutathione $(\mathrm{GSH})$ level $(p<0.01)$ in a dose-response manner. The mitochondrial membrane potential (MMP) of EEGT-treated OSCC cells was significantly decreased in a dose-response manner $(p<0.005)$. In conclusion, we have demonstrated that EEGT induced the growth inhibition
\end{abstract}


and apoptosis of OSCC cells, which was accompanied by ROS increase, GSH depletion, caspase activation, and mitochondrial depolarization. Therefore, EEGT may have potent antitumor effect against oral cancer cells.

Keywords: oral cancer; apoptosis; ROS; glutathione; mitochondrial membrane potential; marine natural product

\section{Introduction}

Oral squamous cell cancer (OSCC) has high morbidity and mortality rates across the world because it is frequently found in advanced stages before therapy [1,2]. The conventional strategies of OSCC management still depend on surgery, radiotherapy, chemotherapy and targeted therapy [3]. The poor outcome of chemotherapy to OSCC contributes to the poor prognosis for OSCC [4]. Therefore, novel, effective therapy for OSCC treatment is still needed.

Marine natural products provide abundant resources for antitumor drug discovery [5,6]. Recently, algae preparations have become a popular treatment in alternative medicine. Gracilaria algae have been cultivated in Taiwan for at least 50 years [7] and are abundant and cheap and used in natural medicines. Many species of Gracilaria algae are well established to be a potential source for drug discovery in natural medicines due to their antibacterial, antiviral, antifungal, antihypertensive, cytotoxic, spermicidal, embriotoxic, and anti-inflammatory effects [8]. However, the species Gracilaria tenuistipitata in Taiwan is not included in this review. Therefore, we were interested in the biological effects of different extracts of $G$. tenuistipitata. Previously, we have demonstrated that the water extracts of $G$. tenuistipitata can reduce the hydrogen peroxide-induced oxidative DNA damage [9]. However, the cellular response to the ethanol extracts of G. tenuistipitata (EEGT) was still unknown. Hence, in this study the biological effects for ethanolic extracts of EEGT on oral cancer cells were examined. We evaluated the possible antiproliferative effects against OSCC (Ca9-22) cells by EEGT as well as its possible mechanism involving apoptosis and oxidative stress.

\section{Results}

\subsection{Cytotoxicity Effects of EEGT-Treated Ca9-22 Oral Cancer Cells}

In the MTS assay (Figure 1), the relative cell viability at various concentrations of EEGT $(0,0.5,1$, $1.5,2$ and $2.5 \mathrm{mg} / \mathrm{mL}$ ) after $24 \mathrm{~h}$ were $100.0 \pm 2.8,106.7 \pm 2.2,85.5 \pm 1.2,57.5 \pm 0.4,25.3 \pm 0.7$ and $16.8 \pm 1.1(\mathrm{n}=6)$. The cell viability of EEGT-treated Ca9-22 oral cells significantly decreased in a dose-response manner $(p<0.0001)$. 
Figure 1. Proliferation of Ca9-22 oral cancer cells is inhibited by ethanolic extracts of G. tenuistipitata (EEGT). Cells were incubated with various concentrations of EEGT $(0,0.5$, 1, 1.5, 2 and $2.5 \mathrm{mg} / \mathrm{mL}$ ) for $24 \mathrm{~h}$. Cell viability was determined by MTS assay. Data are expressed as mean \pm S.D. $(n=6)$. Differences between treatments of different concentrations containing the same capital letter at the top of each column are not significant.

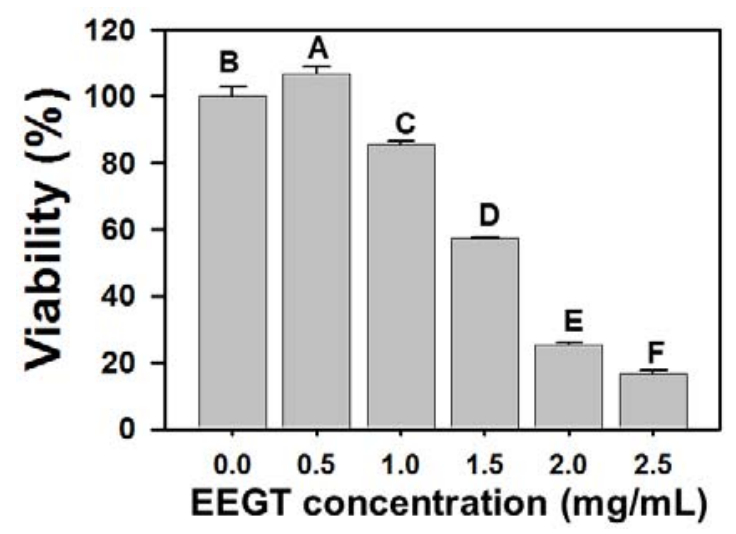

\subsection{Apoptosis Induction of EEGT-Treated Ca9-22 Oral Cells}

In Figure 2a, the profiles of annexin V-positive percentages were shown for the treatments with vehicle control or $0.5,1,1.5,2$ and $2.5 \mathrm{mg} / \mathrm{mL}$ of EEGT for $24 \mathrm{~h}$. After $24 \mathrm{~h}$ EEGT treatment, the annexin $\mathrm{V}$-positive percentages of Ca9-22 oral cancer cells were significantly increased in a dose-response manner for most concentrations ( $p<0.05$ to 0.0001 ) (Figure $2 b$ ).

Figure 2. Ethanolic extracts of $G$. tenuistipitata (EEGT) induced apoptosis of Ca9-22 oral cancer cells. (a) Cells treated with different concentrations (0 to $2.5 \mathrm{mg} / \mathrm{mL}$ ) of EEGT for $24 \mathrm{~h}$ were stained with annexin V-FITC. Positive \% is indicated in each panel; (b) Quantificative analysis of annexin V-positive population. Data are presented as mean \pm S.D. $(n=3)$. Differences between treatments of different concentrations containing the same capital letter at the top of each column are not significant.

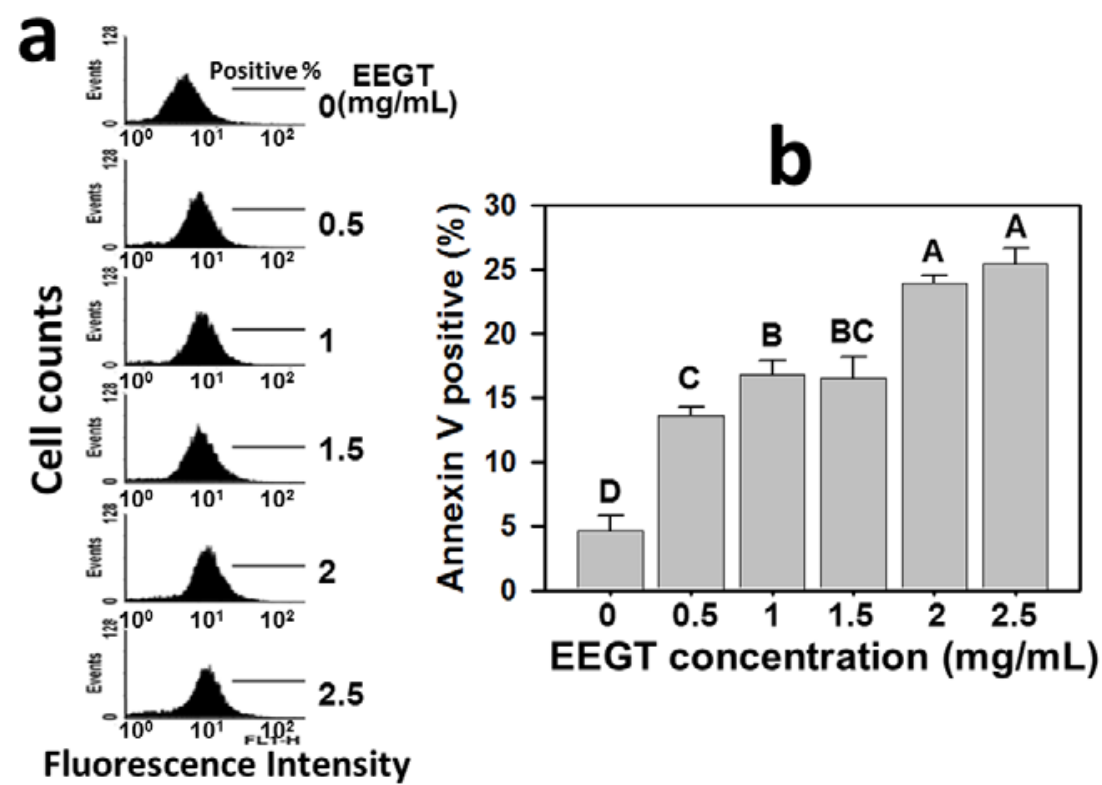




\subsection{Activation of Pan-Caspase in EEGT-Treated Ca9-22 Oral Cancer Cells}

The role of caspases in the EEGT-induced apoptosis of Ca9-22 oral cancer cells was examined by the flow cytometry-based TF2-VAD-FMK assay (Figure 3). The pan-caspase activities were increased at concentrations from 0 to $2.5 \mathrm{mg} / \mathrm{mL}$ EEGT (Figure 3a). Apparently, the generic caspase activities in cells treated with EEGT ranging from 0.5 to $2 \mathrm{mg} / \mathrm{mL}$ showed a significant increase in a dose-response manner $(p<0.0001)$ (Figure 3b).

Figure 3. Ethanolic extracts of $G$. tenuistipitata (EEGT) induced activation of generic caspase in Ca9-22 oral cancer cells. (a) Cells treated with different concentrations ( 0 to $2.5 \mathrm{mg} / \mathrm{mL}$ ) of EEGT for $24 \mathrm{~h}$ were stained with $1 \mu \mathrm{L} 500 \mathrm{X}$ TF2-VAD-FMK. Positive \% is indicated in each panel; (b) Quantificative analysis of pan-caspase fluorescent intensity. Data are presented as mean \pm S.D. $(n=3)$. Differences between treatments of different concentrations containing the same capital letter at the top of each column are not significant.

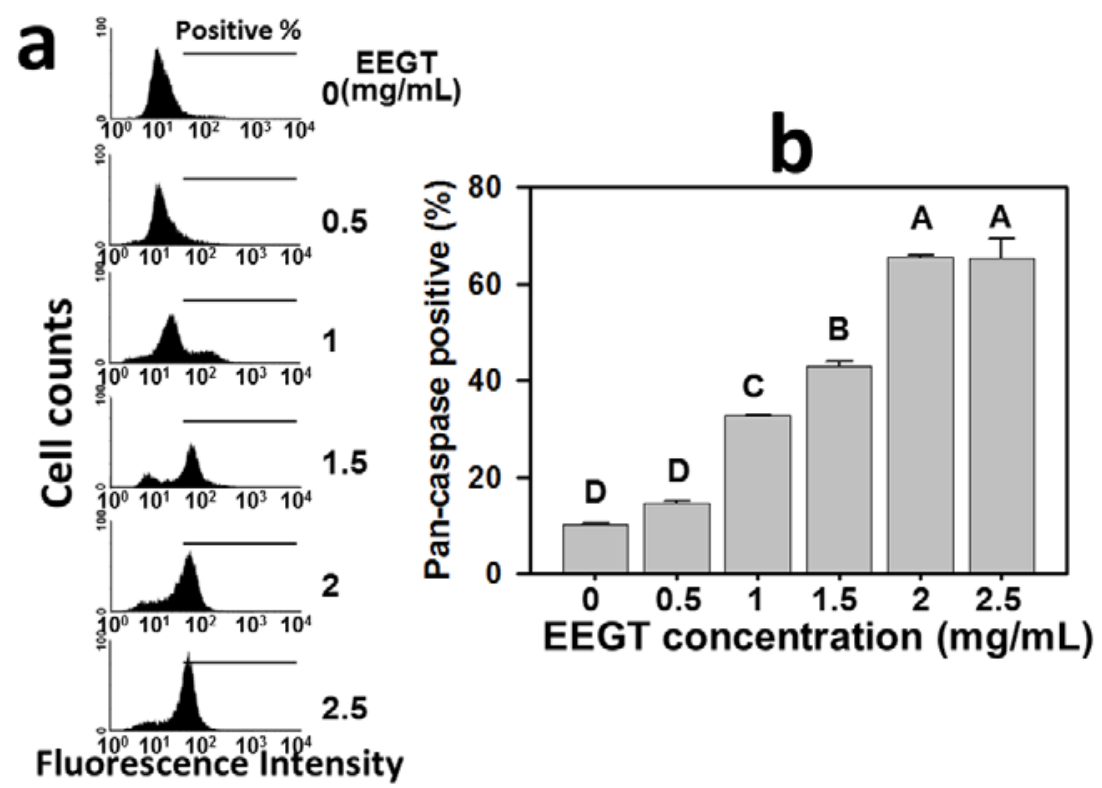

\subsection{Induction of Reactive Oxygen Species (ROS) in EEGT-Treated Ca9-22 Oral Cancer Cells}

The role of ROS in the EEGT-induced apoptosis of Ca9-22 oral cancer cells was examined by the flow cytometry-based DCFH-DA assay (Figure 4). The profiles of ROS-positive percentages of 0, 0.5, 1, 1.5, 2 and $2.5 \mathrm{mg} / \mathrm{mL}$ EEGT for $24 \mathrm{~h}$ were shown (Figure 4a). The ROS-positive percentages of EEGT-treated Ca9-22 oral cancer cells were significantly increased in a dose-response manner after $1.5 \mathrm{mg} / \mathrm{mL}(p<0.0001)$ (Figure $4 \mathrm{~b})$.

\subsection{Depletion of Intracellular Reduced Glutathione (GSH) in EEGT-Treated Ca9-22 Oral Cancer Cells}

The role of GSH in the EEGT-induced ROS change of Ca9-22 oral cancer cells was examined by the flow cytometry-based CMF-DA assay. The profiles of GSH-positive percentages of 0, 0.5, 1, 1.5, 2 and $2.5 \mathrm{mg} / \mathrm{mL}$ EEGT for $24 \mathrm{~h}$ were shown (Figure 5a). The GSH-positive percentages of EEGT-treated Ca9-22 oral cancer cells were significantly reduced in a dose-response manner $(p<0.01)$ (Figure $5 b)$. 
Figure 4. Ethanolic extracts of $G$. tenuistipitata (EEGT) increased reactive oxygen species (ROS) levels of Ca9-22 oral cancer cells. (a) Flow cytometry-based ROS profiles for EEGT-treated cells. Cells treated with different concentrations (0 to $2.5 \mathrm{mg} / \mathrm{mL}$ ) of EEGT for $24 \mathrm{~h}$. Positive \% is indicated in each panel; (b) Quantificative analysis of DCF-positive population. Data are presented as mean \pm S.D. $(n=3)$. Differences between treatments of different concentrations containing the same capital letter at the top of each column are not significant.

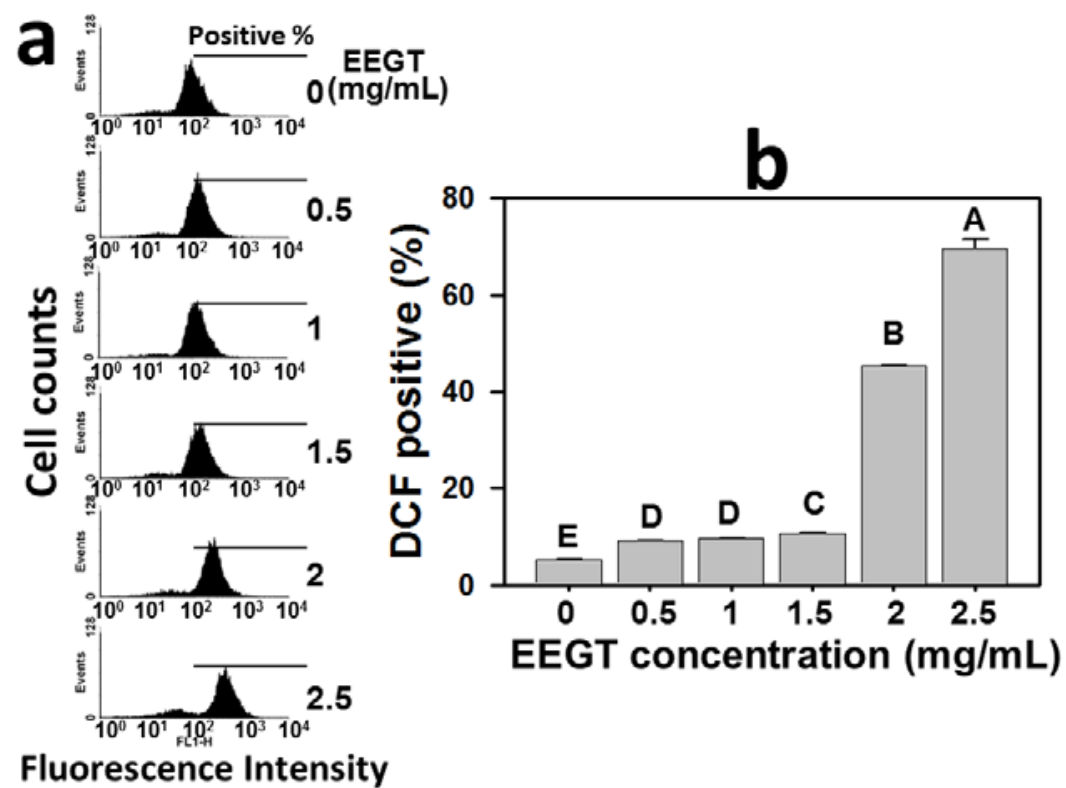

Figure 5. Ethanolic extracts of $G$. tenuistipitata (EEGT) induced glutathione (GSH) depletion of Ca9-22 oral cancer cells. (a) Flow cytometry-based GSH profiles for EEGT-treated cells. Cells treated with different concentrations ( 0 to $2.5 \mathrm{mg} / \mathrm{mL}$ ) of EEGT for $24 \mathrm{~h}$. Positive \% is indicated in each panel; (b) Quantificative analysis of CMF-positive \%. Data are presented as mean \pm S.D. $(n=3)$. Differences between treatments of different concentrations containing the same capital letter at the top of each column are not significant.

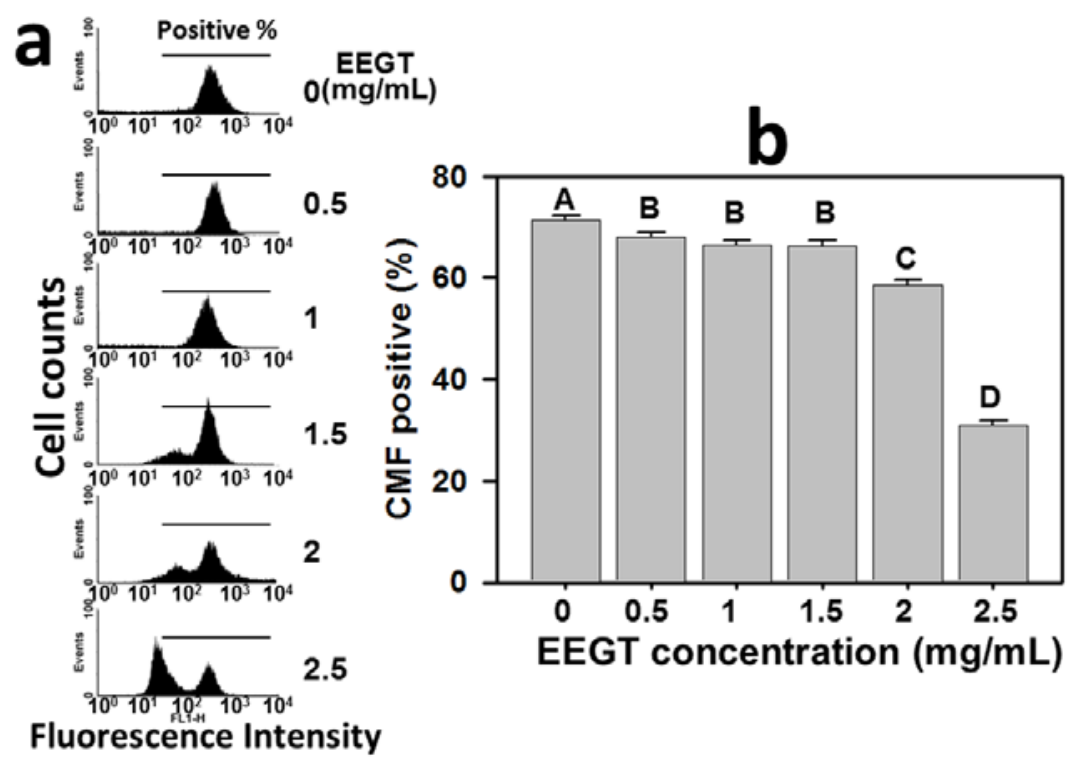




\subsection{Mitochondrial Membrane Potential (MMP) Decrease in EEGT-Treated Ca9-22 Oral Cancer Cells}

The role of MMP in the EEGT-induced ROS change of Ca9-22 oral cancer cells was examined by the flow cytometry-based $\mathrm{DiOC}_{2}(3)$ assay. The profiles of $\mathrm{DiOC}_{2}(3)$-positive percentages of $0,0.5,1$, 1.5, 2 and $2.5 \mathrm{mg} / \mathrm{mL}$ EEGT for $24 \mathrm{~h}$ were shown (Figure 6a). The $\mathrm{DiOC}_{2}(3)$-positive percentages of EEGT-treated Ca9-22 oral cancer cells was significantly reduced in a dose-response manner $(p<0.005)$ (Figure 6b).

Figure 6. Ethanolic extracts of $G$. tenuistipitata (EEGT) reduced mitochondrial membrane potential (MMP) in Ca9-22 oral cancer cells. (a) Flow cytometry-based MMP profiles for EEGT-treated cells. Cells treated with different concentrations (0 to $2.5 \mathrm{mg} / \mathrm{mL}$ ) of EEGT for $24 \mathrm{~h}$. Positive \% is indicated by horizontal lines; (b) Quantificative analysis of $\mathrm{DiOC}_{2}(3)$ intensity. Data are presented as mean \pm S.D. $(n=3)$. Differences between treatments of different concentrations containing the same capital letter at the top of each column are not significant.

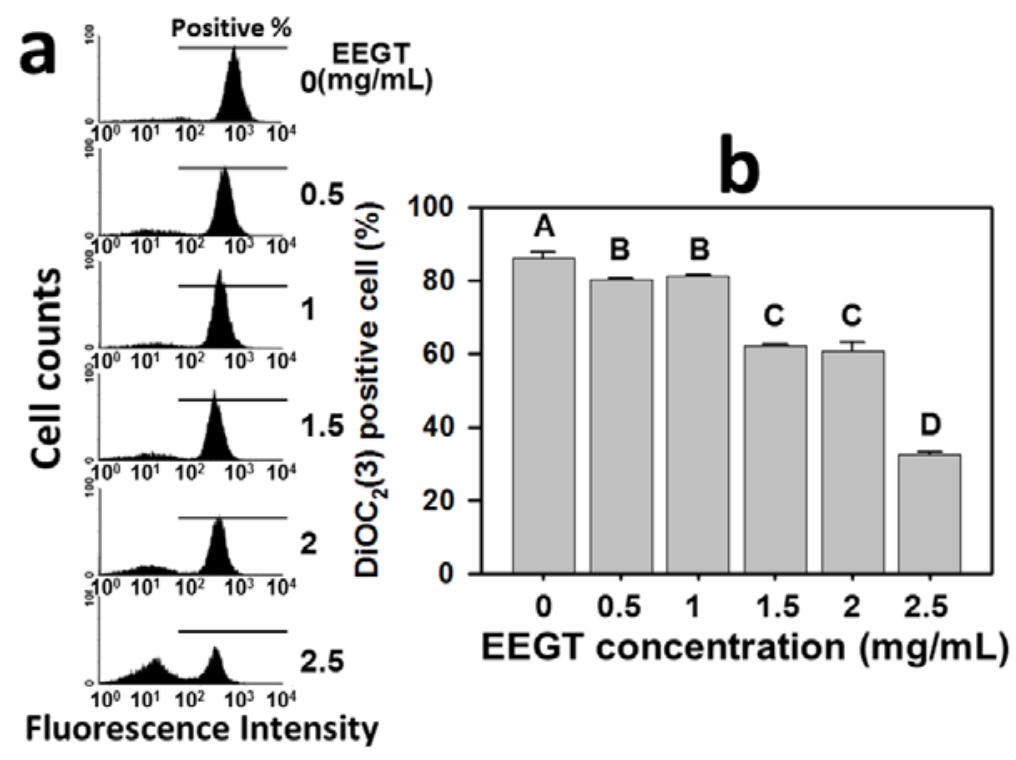

\subsection{Discussion}

In our previous work, we found that the water extracts of $G$. tenuistipitata (AEGT) reduced hydrogen peroxide-induced oxidative DNA damage [9]. In this study, we further demonstrated that EEGT has antiproliferative effects against Ca9-22 oral cancer cells in a dose-dependent manner. To reduce possible toxic effect to normal cells under the current dosage, future work with the active fraction may reduce the dosage of the EEGT. We have found that AEGT has more vitamin $\mathrm{C}$ content than EEGT (data not shown) and it may contribute to the higher anti-oxidative activity of AEGT. Similar to other natural products, the water extract of Portulaca oleracea was reported to significantly inhibit DNA damage, while its ethanolic extract had no effect [10]. These results suggest that different extraction reagents may result in different formulations that generate different functions [11].

Similar to our finding of the anti-oral cancer effect of EEGT, several ethanolic extracts of natural products have demonstrated potential antiproliferative effects in cancer; such as Corydalis yanhusuo against breast cancer [12], Dunaliella salina, Spirulina platensis, and Aphanizomenon flos-aquae 
against leukemic cells [13], propolis against cervical cancer [14], Corchorus olitorius against liver cancer [15], and Scutellaria baicalensis against lung cancer [16]. However, some ethanolic extracts of natural products may display chemopreventive effects towards cancer rather than cytotoxic effects as described above. For example, the ethanolic extract of the red algae Laurencia tristicha possesses antioxidative activity and decreases DNA damage [17]. The ethanolic extract of the brown algae Sargassum dentifolium has potential hepatoprotective effects [18]. Therefore, the antiproliferative effects of ethanolic extracts of natural products seem to vary between species.

Modulating the cell death associated pathways is a successful strategy for cancer therapy [19-22]. For example, many natural product-derived compounds have demonstrated an apoptosis-related antiproliferative effect on cancer, such as protoapigenone [23] and 4 $\beta$-hydroxywithanolide E [24] for lung cancer cells, dryofragin [25] for breast cancer cells, and berberine [26], and goniothalamin [27] for oral cancer cells. Similarly, we found that the annexin V staining intensity of Ca9-22 oral cancer cells was increased in a dose-dependent manner (Figure 2). Both extrinsic and intrinsic pathways of apoptosis have been reported to converge at the level of the effector caspases [28,29]. To further confirm the involvement of apoptosis, the caspase activation in EEGT-treated oral cancer cells was performed. The general caspase activities were increased in a dose-dependent manner for EEGT treatment (Figure 3). Therefore, the EEGT-induced antiproliferative effect in OSCC cells may be partly due to apoptosis.

Cancer cells have an increased basal oxidative stress [30]. The high levels of ROS in cancer cells make cancer cells sensitive to treatments that further increase ROS levels [31]. The strategy of modulating the oxidative stress to drug discovery for anti-cancer studies has been proposed [31,32]. Accordingly, the present study validated this strategy by the finding that EEGT induced the ROS generation in OSCC cells in a dose-response manner (Figure 4). Moreover, some anticancer therapies have demonstrated that GSH depletion can increase ROS generation and further induces apoptosis in glioma [33], leukemia [34], and colon cancer [35]. In the same fashion, we found that GSH was depleted in the EEGT-treated oral cancer cells in a dose-response manner (Figure 5). These results suggest that the oxidative stress plays an important role in the antiproliferative effect of EEGT against OSCC cells.

It has been shown that ROS induction can depolarize the mitochondrial membrane potential, which eventually increases the expression of pro-apoptotic molecules [36,37]. For example, ergocalciferol induced apoptosis of leukemia cells by causing mitochondria dysfunction through ROS production, GSH depletion, caspase activation, and Fas induction [38]. Similarly, the present study demonstrated that EEGT significantly decreased the MMP in OSCC cells in a dose-response manner, suggesting that EEGT-induced mitochondria dysfunction may modulate the oxidative stress and lead to apoptosis in OSCC cells.

\section{Experimental}

\subsection{Raw Materials and Ethanol Extract Preparation}

The fresh seaweed Gracilaria tenuistipitata was collected in spring of 2009 from a marine culture farm at Kouhu Beach, Yunlin County, Taiwan. The dried sample was prepared as described previously [9]. 
Dried samples $(50 \mathrm{~g})$ were soaked in ethanol $(250 \mathrm{~mL})$ three times and extracted with $1,000 \mathrm{~mL}$ of $99.9 \%$ ethanol with shaking at room temperature for $24 \mathrm{~h}$. Then the ethanol extract solution was filtered with Whatman No. 1 filter paper three times and evaporated to dryness at $40 \pm 2{ }^{\circ} \mathrm{C}$ on a rotary evaporator (Buchi Laboratoriums-Technik, Flawil, Switzerland). The dry extract was stored in a sealed container at $-20^{\circ} \mathrm{C}$ until use.

\subsection{Cell Cultures}

The human OSCC cancer cell line Ca9-22 [27] was cultured in DMEM medium (Gibco, Grand Island, NY, USA) and supplemented with $10 \%$ fetal bovine serum (FBS), $100 \mathrm{U} / \mathrm{mL}$ penicillin, $100 \mu \mathrm{g} / \mathrm{mL}$ streptomycin, $0.03 \%$ glutamine and $1 \mathrm{mM}$ sodium pyruvate. The cells were maintained at $37{ }^{\circ} \mathrm{C}$ in a humidified atmosphere containing 5\% CO2.

\subsection{Cell Viability Assay}

EEGT was dissolved in DMSO and added to the medium. The final concentration of DMSO was less than $1 \%$. The effects of EEGT on cell viability was estimated by the 3-(4,5-dimethylthiazol-2-yl)(3-carboxymethoxyphenyl)-2-(4-sulphophenyl)-2H-tetrazolium (MTS) assay (CellTiter 96 AQueous One Solution, Promega, Madison, WI, USA) [39]. Briefly, cells were plated at a density of $1 \times 10^{5}$ cells/well in a 96-well cell culture plate and treated with EEGT at doses of $0.5,1,1.5,2$ and $2.5 \mathrm{mg} / \mathrm{mL}$ for $24 \mathrm{~h}$. After incubation, the MTS solution was added to cells $(10 \mu \mathrm{L}$ per well) and continued to incubate for $1-2 \mathrm{~h}$ at $37^{\circ} \mathrm{C}$. The absorbance at $490 \mathrm{~nm}$ was measured using Dynex MRX Model 96 Well Plate Reader (MTX Lab Systems, Inc., Vienna, VA, USA).

\subsection{Apoptosis Assay}

Apoptosis was measured by annexin V kit (Pharmingen, San Diego, CA, USA) as previously described [40]. Briefly, cells were treated with vehicle or increasing concentrations of EEGT for $24 \mathrm{~h}$. Then, cells were incubated with $10 \mu \mathrm{g} / \mathrm{mL}$ of annexin V-fluorescein isothiocyanate (FITC) and analyzed using the FACSCalibur flow cytometer.

\subsection{Pan-Caspase Activity Assay}

The generic activation of caspases (Caspase-1, 3, 4, 5, 6, 7, 8, 9) was measured by the generic caspase activity assay kit (Abcam, Cambridge, UK). Most caspases have substrate selectivity for the peptide sequence Val-Ala-Asp (VAD). Nontoxic TF2-VAD-FMK is a fluorescent reporter for most caspase activities because it is cell permeable and irreversibly binds to these activated caspases. Briefly, EEGT-treated Ca9-22 cells were suspended in $0.5 \mathrm{~mL}$ warm medium at a density of approximately $1 \times 10^{6}$ cells/mL, added $1 \mu \mathrm{L}$ of $500 \mathrm{X}$ TF2-VAD-FMK, and incubated at $37{ }^{\circ} \mathrm{C}, 5 \% \mathrm{CO}_{2}$, for $1 \mathrm{~h}$. Cells were washed with PBS twice and resuspended in $0.5 \mathrm{~mL}$ of assay buffer for immediate measurement using flow cytometry with excitation and emission settings of 480 and $525 \mathrm{~nm}$, respectively. 


\subsection{Intracellular Reactive Oxygen Species (ROS) Assay}

Intracellular ROS levels were measured using 2',7'-dichlorodihydrofluorescein diacetate (DCFH-DA) as previously described [41]. Briefly, EEGT-treated cells were washed with PBS twice and then mixed with $10 \mu \mathrm{M}$ H2DCF-DA in PBS for $30 \mathrm{~min}$ at $37{ }^{\circ} \mathrm{C}$ in the $\mathrm{CO}_{2}$ incubator. Cells were collected and washed twice with PBS. After centrifugation, cells were resuspended in PBS and immediately measured by the FACSCalibur flow cytometer with excitation and emission settings of 480 and $525 \mathrm{~nm}$, respectively.

\subsection{Intracellular Reduced Glutathione (GSH) Assay}

Intracellular GSH was measured using 5-chloromethylfluorescein diacetate (CMF-DA) as previously described [41]. Briefly, EEGT-treated cells were incubated with $5 \mu \mathrm{M}$ CMF-DA for 20 min at $37^{\circ} \mathrm{C}$ in the $\mathrm{CO}_{2}$ incubator. After washing with PBS, cells were harvested by centrifugation, and then measured with the FACS-Calibur flow cytometer.

\subsection{Mitochondrial Membrane Potential Assay}

Mitochondrial membrane potential (MMP) was examined using a MitoProbe ${ }^{\mathrm{TM}} \mathrm{DiOC}_{2}(3)$ assay kit (Invitrogen, San Diego, CA, USA). Briefly, EEGT-treated Ca9-22 cells were suspended in $1 \mathrm{~mL}$ of warm PBS at approximately $1 \times 10^{6}$ cells $/ \mathrm{mL}$, loaded with $5 \mu \mathrm{L}$ of $10 \mu \mathrm{M} \mathrm{DiOC} 2(3)$, and incubated at $37{ }^{\circ} \mathrm{C}$ in the $\mathrm{CO}_{2}$ incubator for 20 to $30 \mathrm{~min}$. Subsequently, cells were collected, washed and resuspended in PBS for immediate analysis using a flow cytometry assay with excitation and emission settings of 480 and $525 \mathrm{~nm}$, respectively.

\subsection{Statistical Analysis}

All data are presented as mean \pm S.D. Comparison between experimental groups was assessed by one-way ANOVA with Tukey's HSD Post Hoc Test using the software JMP ${ }^{\circledR} 9$ software. Differences between treatments of different concentrations containing the same capital letter are not significant.

\section{Conclusions}

In this study, we have demonstrated that EEGT has an antiproliferative effect against oral cancer cells by induction of apoptosis and the modulation of oxidative stress. These findings not only suggest that EEGT is a promising natural product extract for potential use in oral cancer therapy, but also demonstrate that finding compounds capable of inducing apoptosis and ROS is a promising strategy for anti-oral cancer drug discovery.

\section{Acknowledgments}

We thank the National Science Council of Taiwan for grant (NSC98-2314-B-037-035), and for grants from Department of Health (DOH101-TD-C-111-002), Kaohsiung Medical University Research Foundation (KMUER014 and KMU-M110001), and NSYSU-KMU JOINT RESEARCH PROJECT (\#NSYSUKMU 101-006). 


\section{Conflicts of Interest}

The authors declare no conflict of interest.

\section{References}

1. Warnakulasuriya, S. Global epidemiology of oral and oropharyngeal cancer. Oral Oncol. 2009, 45, 309-316.

2. Johnson, N.W.; Warnakulasuriya, S.; Gupta, P.C.; Dimba, E.; Chindia, M.; Otoh, E.C.; Sankaranarayanan, R.; Califano, J.; Kowalski, L. Global oral health inequalities in incidence and outcomes for oral cancer: Causes and solutions. Adv. Dent. Res. 2011, 23, 237-246.

3. Scully, C.; Bagan, J. Oral squamous cell carcinoma overview. Oral Oncol. 2009, 45, 301-308.

4. Myoung, H.; Hong, S.P.; Yun, P.Y.; Lee, J.H.; Kim, M.J. Anti-cancer effect of genistein in oral squamous cell carcinoma with respect to angiogenesis and in vitro invasion. Cancer Sci. 2003, 94, 215-220.

5. Bhatnagar, I.; Kim, S.K. Marine antitumor drugs: Status, shortfalls and strategies. Mar. Drugs 2010, 8, 2702-2720.

6. Suarez-Jimenez, G.M.; Burgos-Hernandez, A.; Ezquerra-Brauer, J.M. Bioactive peptides and depsipeptides with anticancer potential: Sources from marine animals. Mar. Drugs 2012, 10, 963-986.

7. Ajisaka, T.; Chiang, Y.M. Recent status of Gracilaria cultivation in Taiwan. Hydrobiologia 1993, 260/261, 335-338.

8. De Almeida, C.L.; Falcao Hde, S.; Lima, G.R.; Montenegro Cde, A.; Lira, N.S.; de Athayde-Filho, P.F.; Rodrigues, L.C.; de Souza Mde, F.; Barbosa-Filho, J.M.; Batista, L.M. Bioactivities from marine algae of the genus gracilaria. Int. J. Mol. Sci. 2011, 12, 4550-4573.

9. Yang, J.I.; Yeh, C.C.; Lee, J.C.; Yi, S.C.; Huang, H.W.; Tseng, C.N.; Chang, H.W. Aqueous extracts of the edible Gracilaria tenuistipitata are protective against $\mathrm{H}_{2} \mathrm{O}_{2}$-induced DNA damage, growth inhibition, and cell cycle arrest. Molecules 2012, 17, 7241-7254.

10. Behravan, J.; Mosafa, F.; Soudmand, N.; Taghiabadi, E.; Razavi, B.M.; Karimi, G. Protective effects of aqueous and ethanolic extracts of Portulaca oleracea L. aerial parts on H2O2-induced DNA damage in lymphocytes by comet assay. J. Acupunct. Meridian Stud. 2011, 4, 193-197.

11. Yang, C.H.; Li, R.X.; Chuang, L.Y. Antioxidant activity of various parts of Cinnamomum cassia extracted with different extraction methods. Molecules 2012, 17, 7294-7304.

12. Xu, Z.; Chen, X.; Zhang, Q.; Chen, L.; Wang, Y. Corydalis yanhusuo W.T. Wang extract inhibits MCF-7 cell proliferation by inducing cell cycle G2/M arrest. Am. J. Chin. Med. 2011, 39, 579-586.

13. Bechelli, J.; Coppage, M.; Rosell, K.; Liesveld, J. Cytotoxicity of algae extracts on normal and malignant cells. Leukemia Res. Treat. 2011, doi:10.4061/2011/373519.

14. Szliszka, E.; Czuba, Z.P.; Domino, M.; Mazur, B.; Zydowicz, G.; Krol, W. Ethanolic extract of propolis (EEP) enhances the apoptosis-inducing potential of TRAIL in cancer cells. Molecules 2009, 14, 738-754.

15. Li, C.J.; Huang, S.Y.; Wu, M.Y.; Chen, Y.C.; Tsang, S.F.; Chyuan, J.H.; Hsu, H.Y. Induction of apoptosis by ethanolic extract of Corchorus olitorius leaf in human hepatocellular carcinoma (HepG2) cells via a mitochondria-dependent pathway. Molecules 2012, 17, 9348-9360. 
16. Gao, J.; Morgan, W.A.; Sanchez-Medina, A.; Corcoran, O. The ethanol extract of Scutellaria baicalensis and the active compounds induce cell cycle arrest and apoptosis including upregulation of p53 and Bax in human lung cancer cells. Toxicol. Appl. Pharmacol. 2011, 254, 221-228.

17. Liang, H.; He, J.; Ma, A.G.; Zhang, P.H.; Bi, S.L.; Shi, D.Y. Effect of ethanol extract of alga Laurencia supplementation on DNA oxidation and alkylation damage in mice. Asia Pac. J. Clin. Nutr. 2007, 16 (Suppl. 1), 164-168.

18. Madkour, F.F.; Khalil, W.F.; Dessouki, A.A. Protective effect of ethanol extract of Sargassum dentifolium (Phaeophyceae) in carbon tetrachloride-induced hepatitis in rats. Int. J. Pharm. Pharm. Sci. 2012, 4, 637-641.

19. Zhang, J.Y. Apoptosis-based anticancer drugs. Nat. Rev. Drug Discov. 2002, 1, 101-102.

20. Kepp, O.; Galluzzi, L.; Lipinski, M.; Yuan, J.; Kroemer, G. Cell death assays for drug discovery. Nat. Rev. Drug Discov. 2011, 10, 221-237.

21. Yeh, C.C.; Yang, J.I.; Lee, J.C.; Tseng, C.N.; Chan, Y.C.; Hseu, Y.C.; Tang, J.Y.; Chuang, L.Y.; Huang, H.W.; Chang, F.R.; et al. Anti-proliferative effect of methanolic extract of Gracilaria tenuistipitata on oral cancer cells involves apoptosis, DNA damage, and oxidative stress. BMC Complement. Altern. Med. 2012, 12, 142.

22. Shang, L.H.; Li, C.M.; Yang, Z.Y.; Che, D.H.; Cao, J.Y.; Yu, Y. Luffa echinata Roxb. induces human colon cancer cell (HT-29) death by triggering the mitochondrial apoptosis pathway. Molecules 2012, 17, 5780-5794.

23. Chiu, C.C.; Chang, H.W.; Chuang, D.W.; Chang, F.R.; Chang, Y.C.; Cheng, Y.S.; Tsai, M.T.; Chen, W.Y.; Lee, S.S.; Wang, C.K.; et al. Fern plant-derived protoapigenone leads to DNA damage, apoptosis, and $\mathrm{G}(2) / \mathrm{m}$ arrest in lung cancer cell line H1299. DNA Cell Biol. 2009, 28, 501-506.

24. Yen, C.Y.; Chiu, C.C.; Chang, F.R.; Chen, J.Y.; Hwang, C.C.; Hseu, Y.C.; Yang, H.L.; Lee, A.Y.; Tsai, M.T.; Guo, Z.L.; et al. 4beta-Hydroxywithanolide E from Physalis peruviana (golden berry) inhibits growth of human lung cancer cells through DNA damage, apoptosis and G2/M arrest. BMC Cancer 2010, 10, 46.

25. Zhang, Y.; Luo, M.; Zu, Y.; Fu, Y.; Gu, C.; Wang, W.; Yao, L.; Efferth, T. Dryofragin, a phloroglucinol derivative, induces apoptosis in human breast cancer MCF-7 cells through ROS-mediated mitochondrial pathway. Chem. Biol. Interact. 2012, 199, 129-136.

26. Ho, Y.T.; Lu, C.C.; Yang, J.S.; Chiang, J.H.; Li, T.C.; Ip, S.W.; Hsia, T.C.; Liao, C.L.; Lin, J.G.; Wood, W.G.; et al. Berberine induced apoptosis via promoting the expression of caspase-8, -9 and -3 , apoptosis-inducing factor and endonuclease G in SCC-4 human tongue squamous carcinoma cancer cells. Anticancer Res. 2009, 29, 4063-4070.

27. Yen, C.Y.; Chiu, C.C.; Haung, R.W.; Yeh, C.C.; Huang, K.J.; Chang, K.F.; Hseu, Y.C.; Chang, F.R.; Chang, H.W.; Wu, Y.C. Antiproliferative effects of goniothalamin on Ca9-22 oral cancer cells through apoptosis; DNA damage and ROS induction. Mutat. Res. 2012, 747, 253-258.

28. Storey, S. Targeting apoptosis: Selected anticancer strategies. Nat. Rev. Drug Discov. 2008, 7, 971-972. 
29. Cha, J.D.; Kim, J.Y. Essential oil from Cryptomeria japonica induces apoptosis in human oral epidermoid carcinoma cells via mitochondrial stress and activation of caspases. Molecules 2012, 17, 3890-3901.

30. Martin-Cordero, C.; Leon-Gonzalez, A.J.; Calderon-Montano, J.M.; Burgos-Moron, E.; Lopez-Lazaro, M. Pro-oxidant natural products as anticancer agents. Curr. Drug Targets 2012, 13, 1006-1028.

31. Montero, A.J.; Jassem, J. Cellular redox pathways as a therapeutic target in the treatment of cancer. Drugs 2011, 71, 1385-1396.

32. Wondrak, G.T. Redox-directed cancer therapeutics: Molecular mechanisms and opportunities. Antioxid. Redox Sign. 2009, 11, 3013-3069.

33. Khan, M.; Yi, F.; Rasul, A.; Li, T.; Wang, N.; Gao, H.; Gao, R.; Ma, T. Alantolactone induces apoptosis in glioblastoma cells via GSH depletion, ROS generation, and mitochondrial dysfunction. IUBMB Life 2012, 64, 783-794.

34. Chen, G.; Chen, Z.; Hu, Y.; Huang, P. Inhibition of mitochondrial respiration and rapid depletion of mitochondrial glutathione by beta-phenethyl isothiocyanate: Mechanisms for anti-leukemia activity. Antioxid. Redox Sign. 2011, 15, 2911-2921.

35. Ong, P.L.; Weng, B.C.; Lu, F.J.; Lin, M.L.; Chang, T.T.; Hung, R.P.; Chen, C.H. The anticancer effect of protein-extract from Bidens alba in human colorectal carcinoma SW480 cells via the reactive oxidative species- and glutathione depletion-dependent apoptosis. Food Chem. Toxicol. 2008, 46, 1535-1547.

36. Simon, H.U.; Haj-Yehia, A.; Levi-Schaffer, F. Role of reactive oxygen species (ROS) in apoptosis induction. Apoptosis 2000, 5, 415-418.

37. Circu, M.L.; Aw, T.Y. Reactive oxygen species, cellular redox systems, and apoptosis. Free Radic. Biol. Med. 2010, 48, 749-762.

38. Chen, W.J.; Huang, Y.T.; Wu, M.L.; Huang, T.C.; Ho, C.T.; Pan, M.H. Induction of apoptosis by vitamin D2, ergocalciferol, via reactive oxygen species generation, glutathione depletion, and caspase activation in human leukemia cells. J. Agric. Food Chem. 2008, 56, 2996-3005.

39. Shin, J.A.; Kim, J.J.; Choi, E.S.; Shim, J.H.; Ryu, M.H.; Kwon, K.H.; Park, H.M.; Seo, J.Y.; Lee, S.Y.; Lim, D.W.; et al. In vitro apoptotic effects of methanol extracts of Dianthus chinensis and Acalypha australis L. targeting specificity protein 1 in human oral cancer cells. Head Neck 2012, doi:10.1002/hed.23072.

40. Chiu, C.C.; Liu, P.L.; Huang, K.J.; Wang, H.M.; Chang, K.F.; Chou, C.K.; Chang, F.R.; Chong, I.W.; Fang, K.; Chen, J.S.; et al. Goniothalamin inhibits growth of human lung cancer cells through DNA damage, apoptosis, and reduced migration ability. J. Agric. Food Chem. 2011, 59, 4288-4293.

41. Wang, H.; Joseph, J.A. Quantifying cellular oxidative stress by dichlorofluorescein assay using microplate reader. Free Radic. Biol. Med. 1999, 27, 612-616.

Sample Availability: Not available.

(C) 2012 by the authors; licensee MDPI, Basel, Switzerland. This article is an open access article distributed under the terms and conditions of the Creative Commons Attribution license (http://creativecommons.org/licenses/by/3.0/). 